\title{
Electro-enhanced Ion Transport through Bulk-Liquid Membrane
}

\author{
Afagh Nasirian and Ali Reza Ghiasvand* \\ Department of Chemistry, Lorestan University, Khoramabad, Iran \\ *E-mail: a_ghiasvand@yahoo.com
}

doi: $10.20964 / 2016.10 .40$

Received: 8 July 2016 / Accepted: 10 August 2016 / Published: 6 September 2016

\begin{abstract}
DC potential-reinforced bulk-liquid membrane transport (PR-BLMT) was studied using Fe (II)-1,10phenanthroline complex (Fe-Phen) as a model, for the first time. Indeed, this electro-enhanced ion transport study was performed by combination of the electro-membrane extraction (EME) and bulkliquid membrane transport (BLMT). Iron (II) ions were transported from $3 \mathrm{~mL}$ aqueous solution $\left(\mathrm{pH}=4.3\right.$ ) into $1.5 \mathrm{~mL}$ of $1.0 \mathrm{M} \mathrm{HNO}_{3}$ solution through $12 \mathrm{~mL}$ dichloromethane containing $5 \times 10^{-3} \mathrm{M}$ 1,10-phenanthroline. Ion transport was significantly improved by applying a DC voltage within the transport process. To maximize the transport, the important experimental variables including $\mathrm{pH}$ and volumes of donor and acceptor phases, ionic strength, type and volume of BLM, extraction time, DC potential, and type of electrode were studied. The results showed that exhaustive transport of Fe (II) ions through organic membrane was possible in the range of $0.2-27 \mu \mathrm{g} \mathrm{mL}^{-1}\left(\mathrm{R}^{2}=0.998\right)$ with a relative standard deviation (RSD) of $3.5 \%(n=8)$. The applicability of the proposed PR-BLMT method to interfering matrices was evaluated by successful transport of $\mathrm{Fe}$ (II) ions in different real water samples.
\end{abstract}

Keywords: Electro-enhanced ion transport; Bulk-liquid membrane; Fe (II) ion; UV-Vis spectrophotometry.

\section{FULL TEXT}

(C) 2016 The Authors. Published by ESG (www.electrochemsci.org). This article is an open access article distributed under the terms and conditions of the Creative Commons Attribution license (http://creativecommons.org/licenses/by/4.0/). 